\title{
Analysis of the microstructural influence by laser cutting velocity
}

\author{
Análisis de la afectación microestructural debida a la velocidad de corte con láser
}

\author{
M. López-Camargo ; A. Martin-Buitrago iD ; R Rodriguez-Baracaldo iD \\ DOI: https://doi.org/10.22517/23447214.23371 \\ Artículo de investigación científica y tecnológica
}

\begin{abstract}
This research evaluates the influence of the $\mathrm{CO}_{2}$ laser cutting velocity in the heat-affected zone in a lowcarbon steel. The control of laser cutting parameters is essential to ensure that the properties required in the material have not been affected, and avoid additional grinding processes on the cut surfaces. Morphologic, mechanic and microstructural tests were used to prove the influence of cutting process and its velocity on heat-affected zone. Transformation from ferritic into pearlitic structure and reduction in grain size were analyzed. Also, was evaluated a rise in hardness due to phase transformation. Better cutting conditions were evidenced in samples using a cutting velocity of $80 \mathrm{~mm} / \mathrm{s}$ because the mean hardness obtained allow infer a good relation of properties and a smaller heat affected zone.
\end{abstract}

Index Terms-, $\mathrm{CO}_{2}$ laser, cutting velocity, heat-affected zone, Laser cutting, pearlitic structure.

Resumen - Esta investigación evalúa la influencia de la velocidad de corte con láser de $\mathrm{CO}_{2}$ en la zona afectada por el calor en un acero de bajo carbono. El control de los parámetros de corte por láser es indispensable para garantizar que las propiedades requeridas en el material no hayan sido afectadas, y evitar procesos adicionales de rectificado en las superficies cortadas. Se utilizaron pruebas morfológicas, mecánicas y microestructurales para demostrar la influencia de la la velocidad de corte en la zona afectada por el calor. Se analiza la transformación ferríta a una estructura perlítica y la reducción en el tamaño de grano. También, se evaluó el aumento en la dureza debido al cambio de fase. Se evidenciaron mejores condiciones de corte en la muestra usando una velocidad de corte de $80 \mathrm{~mm}$ / s considerando la dureza media obtenida permite inferir una buena relación de propiedades y una menor zona afectada por el calor.

Palabras claves - Láser $\mathrm{CO}_{2}$, velocidad de corte, zona afectada por el calor, corte láser, estructura perlítica.

This manuscript was sent on February 07, 2020 and accepted on November 26, 2020.

M. López Camargo is with SENA- Centro de Tecnología de Manufactura Avanzada- Complejo Norte Pedregal. Antioquia- Medellín- Colombia (email: mnlopezc@sena.edu.co).

\section{INTRODUCTION}

$\mathrm{T}$ $\mathrm{HE} \mathrm{CO}_{2}$ laser in industrial use as a cutting tool is versatile furthermore this tool has been exploited for several decades in automotive, aerospace, electronics, textile and plastic industry. It has also been developed in other areas for instance cutting, welding, micro-welding, drilling and even it is used in heat treatment of some materials [1].

From material application point of view, laser cutting has important advantages e.g. A) the energy density, that can be focused in an area of any material, is greater than the energy density used with other technologies. Besides the possibility of reaching high temperatures in short times allows cutting using laser of any kind of material. B) A laser beam, in practice, has no inertia thus it can be focused with optical precision. Consequently, lasers are ideal to automatic control adaptation and fast processed applications of complex shapes [2].

Laser cutting is a process thermally induced, in which, the energy of a laser beam focused is absorbed by the material resulting in vaporization and thus the cut itself. The parameters that may change a laser cut are mostly optical, thermal, electrical and mechanical properties of the material [3]. Aside from the properties of the material, the quality of laser cutting depends on operation parameters like power, velocity and gasses pressure, principally.

The surface of the cut material is almost entirely defined by the striation formation, that is the reason why control the laser cutting parameters in order to get laser cut-edges of high quality even produced with a high cutting velocity [4]. As a result of low laser cutting velocity, heat flows via conduction on the material and predominates convective component, leading into a heat discharge supplementary.

During the cutting process near material edge a severe thermal cycle is experienced as the laser beam passes; this cycle of quick heating and cooling the material induces microstructural changes. The region known as the heat affected zone (HAZ), it is composed by particles of material that did not reached the boiling point nevertheless they have changed their

A. Martin Buitrago is with MoviTec Avanzada SAS, Bogotá, Colombia (email:aldemar@hotmail.com).

R. Rodríguez-Baracaldo, is a Full Professor in the Mechanical and Mechatronics Department, Facultad de Ingeniería, Universidad Nacional de Colombia. (email:rodriguezba@unal.edu.co). 
microstructure because of the heat induced. In steels, laser cutting generates martensitic and pearlitics structures, this transformation depends on the carbon content [5-6], the presence of carbide [7]; equally the grain growth [8] which can be observed in HAZ.

The microstructure modified in HAZ affects the properties and performance of the material, including its behavior against corrosion and wear [8]. The oxidation marks resulted of the cut corresponding to the localized presence of oxides thin layers upon the material surface that is being cut. These marks are easily seen immediately after the laser cut [9-10]. The size and properties of HAZ are also important due to the potential local degradation resulting in edge fragility. The rise of the wide's groove increase the size of stretch marks formed at the surface of the cut edge. The superficial stretch marks are mainly the cause of roughness's edge and are the fundamental feature of the quality laser cutting, as a function of the process of cut edge as properties of work piece. The superficial stretch marks increase their size as laser output power increase, that effect is amplified when the cut edge velocity decrease because of an increasing in the power coupling factor [11].

The quality of laser cutting is defined by the surface condition and the presence of re-solidified material which occurs because of the dross attachment along the cutting edge. There are many non-conformities in the region with that quality, and that is the reason why there are reprocessing delays, why in local levels return their final products and material wasting. Due to the tons quantity of structural steel that is being cut using laser cutting in the country, it is necessary to stablish some parameters that allows improve quality and avoid the problems mentioned. In the consulted literature, there is no information that shows the parameters that must be applied in the cutting cluster in national industry.

This research, alongside the local industry has the objective of determining the cutting laser parameters that generate the least thermal impact in a low-carbon steel sheet. Morphological, micro-structural and mechanical properties are analyzed in the cutting surface and HAZ, to determine velocity parameters adequate for this process.

\section{EXPERIMENTAL PROCEDURE}

\section{A. Material}

Structural steel (ASTM A-36) samples were prepared by cutting $50 \mathrm{~mm} \times 30 \mathrm{~mm}$ sheets using laser $\mathrm{CO}_{2}$. The sheet was cut in 10 fragments, the first one was cut employing a cutting velocity of $20 \mathrm{~mm} / \mathrm{s}$ and for each fragment an addition of 10 $\mathrm{mm} / \mathrm{s}$ in the velocity was performed, see Fig. 1. The sample number 0 is a non-heat affected piece of sheet and it is the reference for the metallographic analysis and micro-hardness. A cut surface analysis was done with an optic microscopy using a Leica stereoscopy.

\begin{tabular}{|c|c|c|c|c|c|c|c|c|c|c|c|c|}
\hline $\mathbf{1}$ & 2 & $\mathbf{2}$ & $\mathbf{3}$ & $\mathbf{4}$ & $\mathbf{5}$ & $\mathbf{6}$ & $\mathbf{7}$ & $\mathbf{8}$ & $\mathbf{9}$ & $\mathbf{1 0}$ \\
\hline 20 & 30 & 40 & 50 & 60 & 70 & 80 & 90 & 100 \\
\hline
\end{tabular}

Fig. 1 Cutting velocity $(\mathrm{mm} / \mathrm{s})$ for each sample.

\section{B. Metallographic preparation}

The samples are cut as shown in Fig. 2a and 2b. Fig. 3 shows the assembly of the cutting surface transversal section on Bakelite with the help of a support.

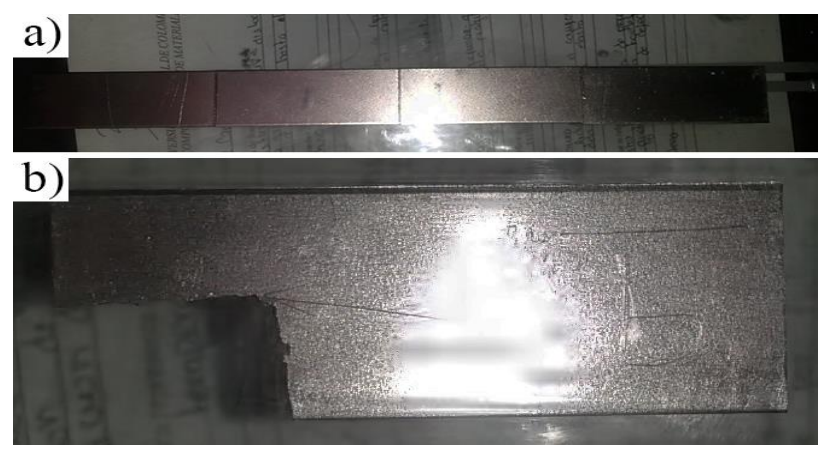

Fig. 2a. Structural steel sheet grade A-36. 2b. Sheet after cutting process. Evaluated surface (transversal section) and heat affected zone resulted of the laser cutting.

Then, the samples were polished until a scratch-free mirror finish. Once obtained this finish, the polished surface was attacked with chemical etchant Nital (solution of nitric acid in ethanol).

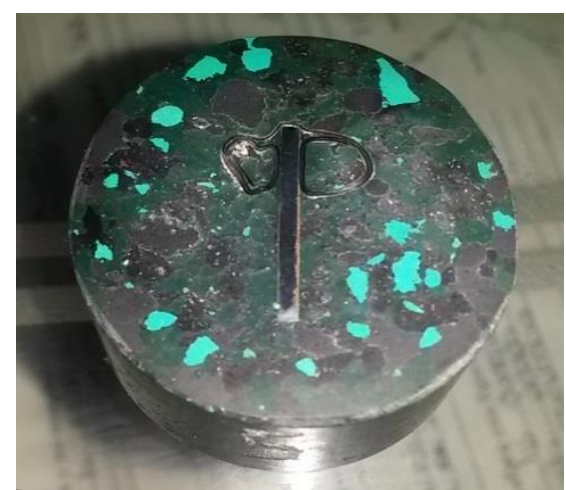

Fig. 3. Assembly of the sheet transversal section in bakelite. Source: Own elaboration

\section{Micro-indentation test.}

Surface mechanical properties were tested using microindentation test. It was used a LECO M400 G2 brand microshore durometer with $50 \mathrm{~g}$ load and Vickers indenter. The number of indentations is determined according to the length of HAZ, in order to compare it with the transition zone and the non-affected zone.

\section{RESULTS AND DISCUSSIONS}

\section{A. Superficial analysis of the laser cutting}

The material was analyzed with the stereograph microscope, and it was found the striation appearance mentioned above; Fig. $4 \mathrm{a}$ and $4 \mathrm{~b}$ correspond to sample number 4 with cutting velocity $50 \mathrm{~mm} / \mathrm{s}$.

Photographs in Fig. 4a show the origin of the stretch marks formed towards the bottom of the notch. The flux of the phenomena resulting of the low viscosity in fusion and greater 
superficial tension, causing instability in the flux and its ondulation, that is probably caused by low cutting velocity.

This behavior was indicated by Sobih and Crouse [10], in their research on striation in "sweet" metal sheets by $\mathrm{CO}_{2}$ cutting laser. With an addition in cutting velocity, each one of the pieces presents a surface less heterogeneous and reducing the presence of striation marks in the medium of the sheet as shown in Fig. 4b.
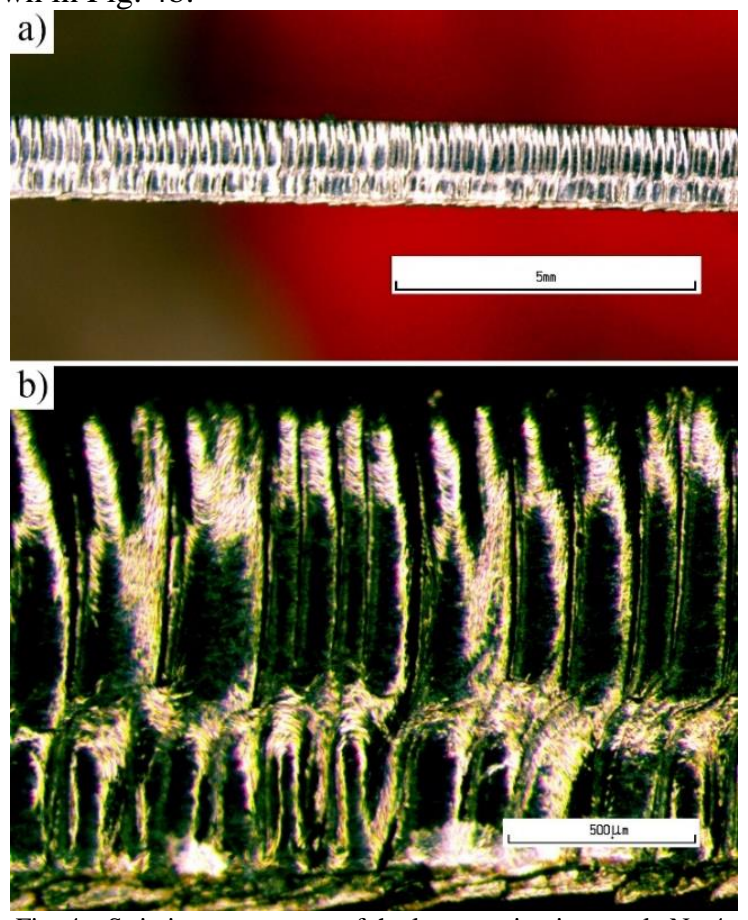

Fig. 4.a Striation appearance of the laser cutting in sample No.4. 4.b Striation in cutting surface.

Fig. 5 illustrates the material loss due to a laser cutting operation, in this case with a cutting velocity of $80 \mathrm{~mm} / \mathrm{s}$.

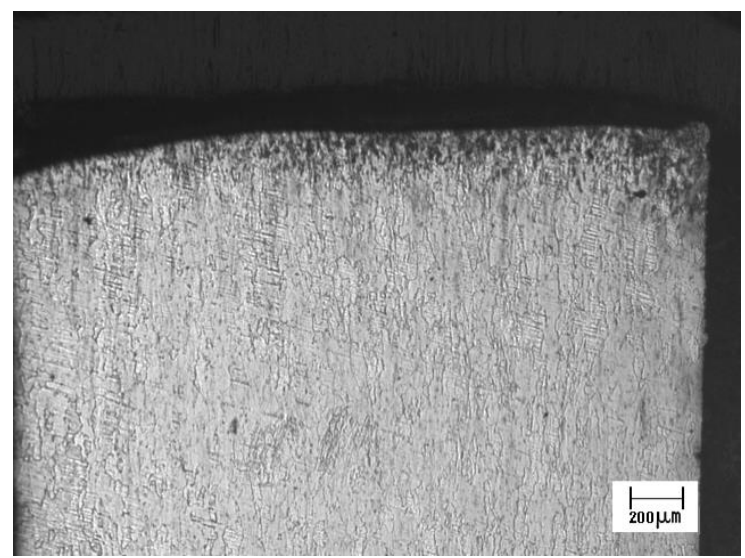

Fig. 5. HAZ appearance 50x (speed: $80 \mathrm{~mm} / \mathrm{s}$.

Fig. 6 shows the micro-structure of the material cut using five times the cutting velocity. All images were taken with the same magnification so a direct comparation can be made, in order to have a better analysis of the micro-structural change. Images also include the average wide of HAZ.

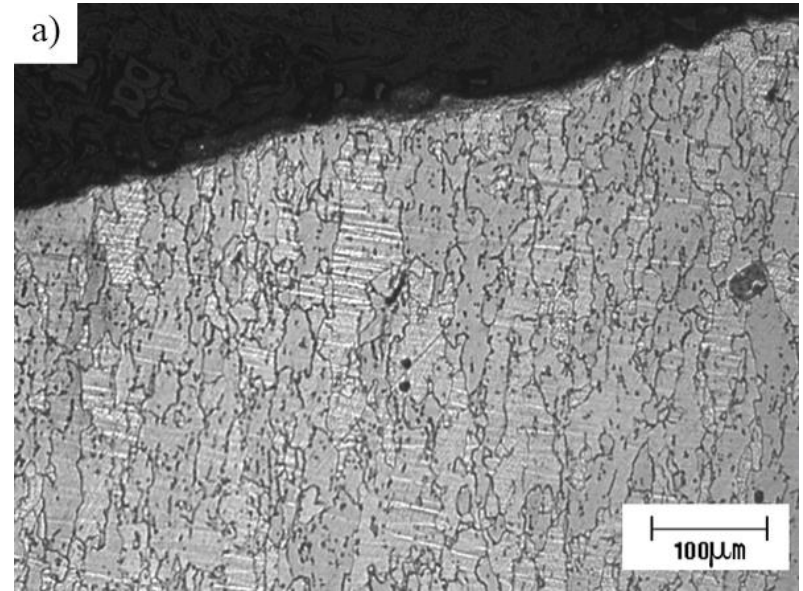

b)

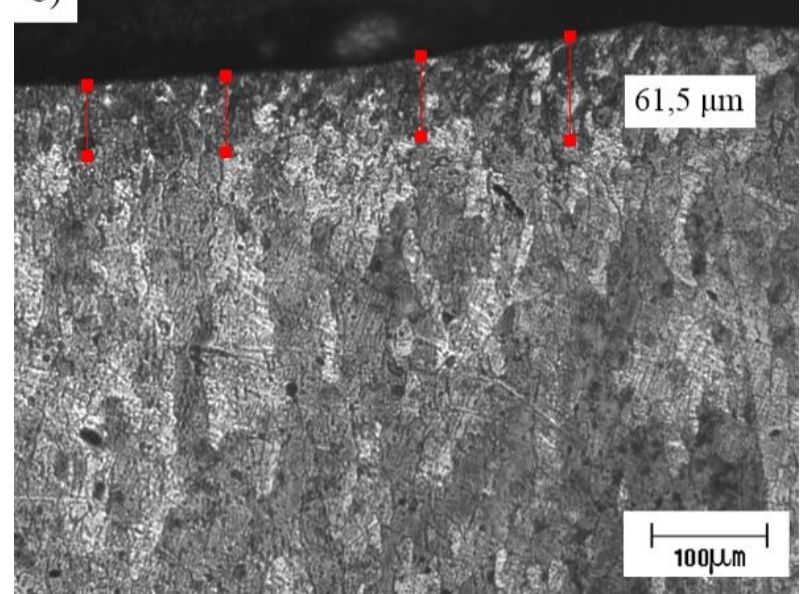

c)

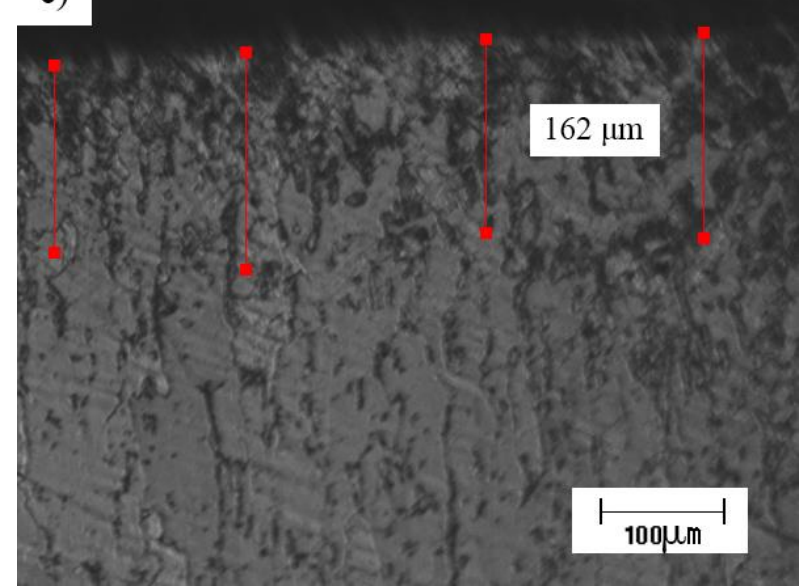



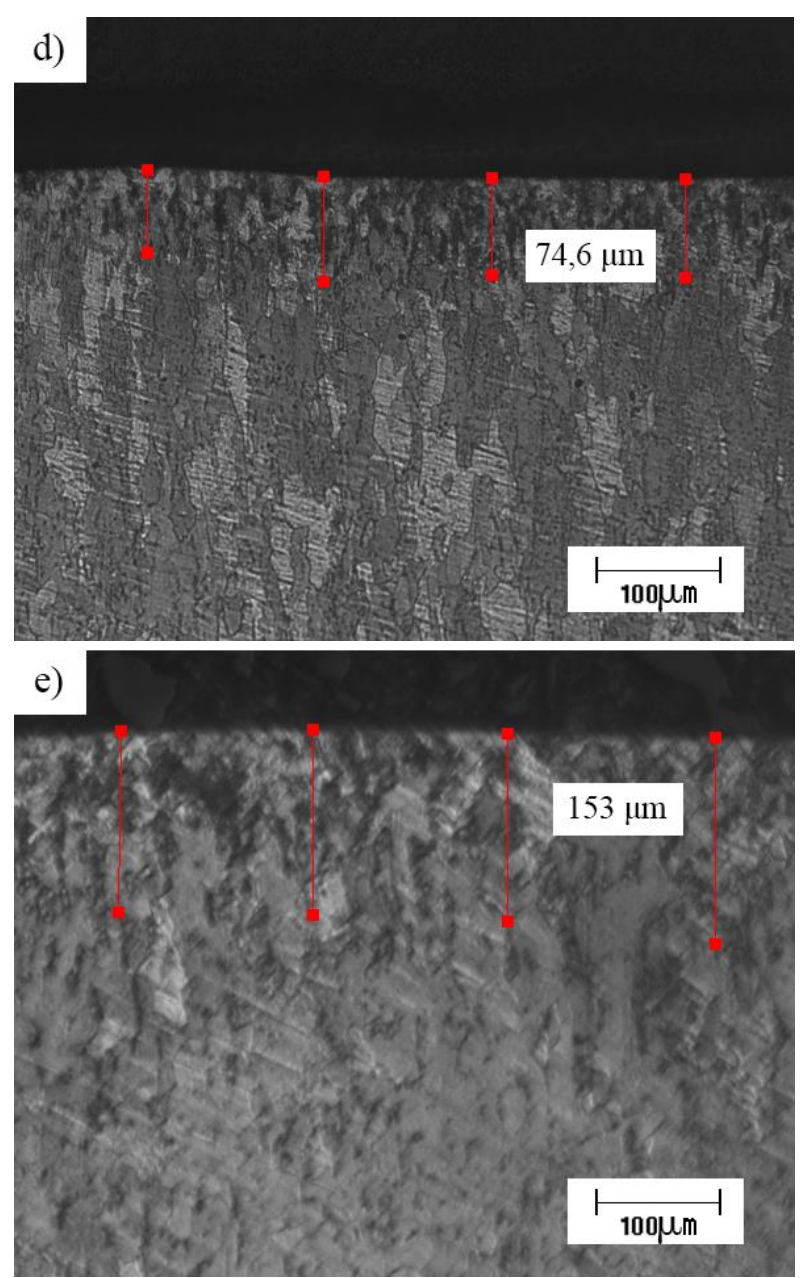

Fig. 6 a) Sample "0", no cut. b) Sample 1, Cutting speed $20 \mathrm{~mm} / \mathrm{s} \mathrm{c}$ ) Sample 5, cutting speed $60 \mathrm{~mm} / \mathrm{s}$ d) Sample 7 cutting speed $80 \mathrm{~mm} / \mathrm{s}$ e) Sample 9 cutting Speed $100 \mathrm{~mm} / \mathrm{s}$

Sample number 7 which was tested with a cutting velocity of $80 \mathrm{~mm} / \mathrm{s}$, presented a low heat affected zone, and material conserved good superficial appearance (Fig. 7). It is evidenced a ferritic structure transformation to perlitic structure, besides a reduction in grain size.

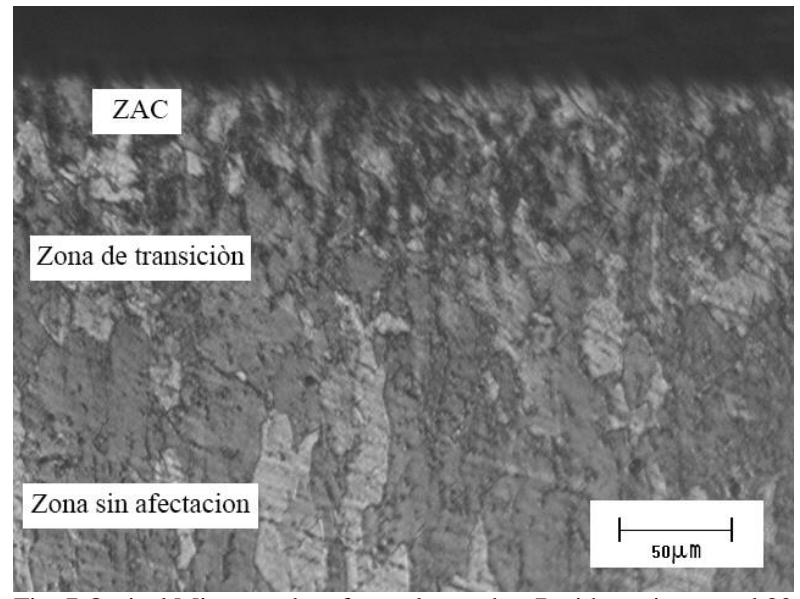

Fig. 7 Optical Micrography of sample number 7 with cutting speed 80 $\mathrm{mm} / \mathrm{s}$.

Fig. 8 shows the notable change of micro-structure inside sample number 7. Petru and Zlamal [12], present a study of $\mathrm{HAZ}$ of a Co-Ni-Cr-W alloy, cut with $\mathrm{CO}_{2}$ laser where the
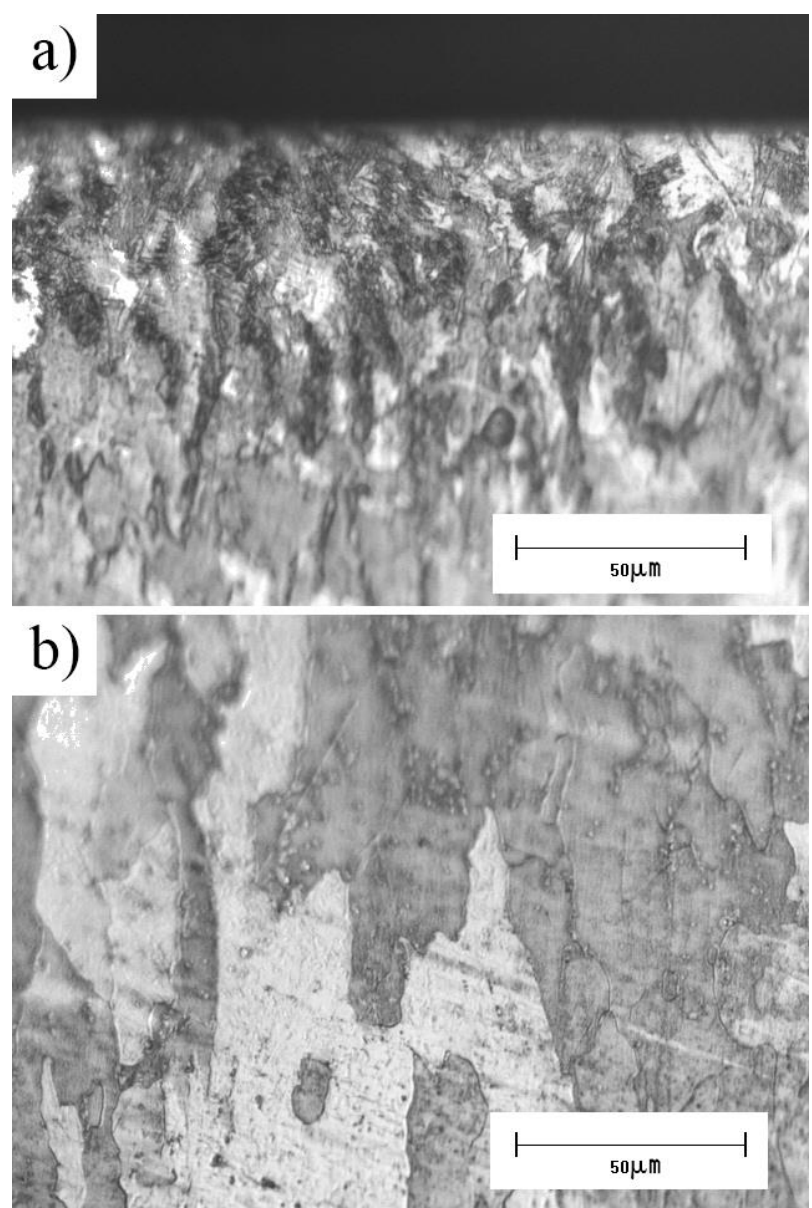

Fig. 8. Fig 8. Optical micrography of a pearltic and ferritic structure inside the sample. A) HAZ with pearlitic transformation b) Nonaffected Zone

micro-structural change is associated with various parameters including cutting velocity. In studies made by Tohmas [13] and Schulz et al. [14], point out that in low-carbon steel cut with laser, ferritic structure undergoes changes to be a martensitic structure. This difference is due to the cooling velocity the managed by Tohmas and Schulz et al.

\section{B. Micro-hardness analysis.}

Indentations were made in HAZ, transition zone and nonaffected zone. Fig. 9 indicates higher hardness at the beginning of the indentation in each of the samples in HAZ and less hardness in the non-affected zone.

The greatest value of hardness was measured in sample number 1 (cutting velocity $20 \mathrm{~mm} / \mathrm{s}$ ) corresponding to the fewest cutting velocity. In the same order of ideas, the lowest value of hardness was found in the sample with the greatest cutting velocity $(100 \mathrm{~mm} / \mathrm{s})$. 


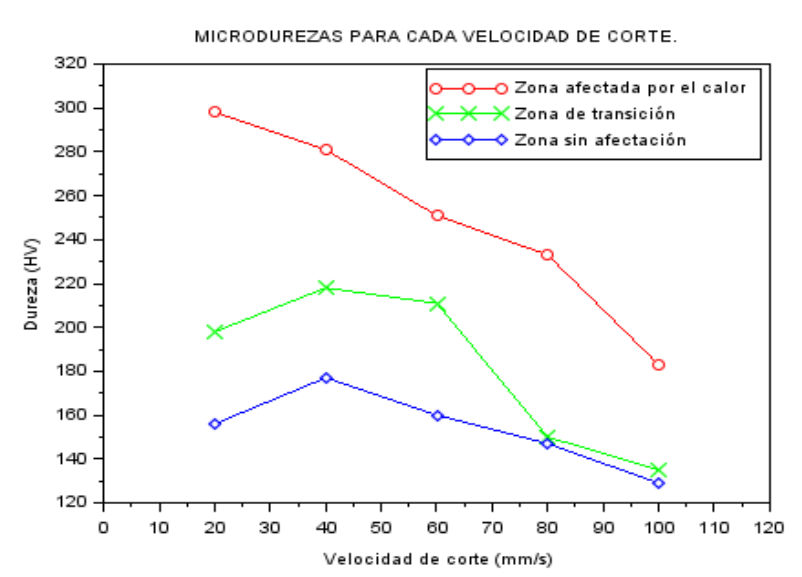

Fig. 9. Microhardness of samples for each cutting speed. Source: Own elaboration

In general terms, with an arise in cutting velocity, hardness in material decrease in the three analysis zones: HAZ, transition and non-affected zone. The greatest hardness found in HAZ is highlighted and the most pronounced drop of hardness according to the increase of the cutting velocity.

\section{CONCLUSIONS}

Better cutting conditions evidenced in sample number 7 which has been cut using a cutting velocity of $80 \mathrm{~mm} / \mathrm{s}$ because of the medium hardness thus allow infer a good relation of properties and a smaller heat affected zone.

Due to the temperature generated by the cutting process, a micro-structural change transformation occurs in the edge of the material. It can be found pearlite that doesn't change material properties in its industrial use.

The rise in micro-hardness in the HAZ presented in all samples, it can be explained as a hardening process by the formation of cementite that follows the presence of pearlite.

Typical laser cut striation is evidenced, because of low cutting velocity. These marks tend to disappear with a rise in cutting velocity, but they do not fully disappear.

\section{ACKNOWLEDGMENT}

We're grateful with Movitec Avanzada SAS for making the cutting test in different conditions, and with Universidad Nacional de Colombia- Bogotá for supporting the research.

\section{REFERENCES}

[1] V. Aboites and G.E. Torres-Cisneros. (1986) Láseres, una introducción, CIO. Reporte Técnico No. 7.

[2] J.M. Orza. (1998). Una introducción a las aplicaciones industriales de los láseres. Aspectos económicos y nuevos desarrollos. Rev. Metal. Madrid. 34(2), pp. 188-193.

DOI: https://doi.org/10.3989/revmetalm.1998.v34.i2.687

[3] L. Bachs, J. Cuesta and N. Carles, Aplicaciones Indsutriales del Laser. Barcelona, España: Marcombo, 1988.

[4] D. Schuöcker. (1987), The Physical Mechanism and Theory of Laser Cutting. The Industrial Laser Annual Handbook, 9, pp. 65-79. DOI: https://doi.org/10.1117/12.937093
[5] S.L. Mannan and M. Valsan. (2006). High-temperature low cycle fatigue, creep-fatigue and thermomechanical fatigue of steels and their welds. Int J of Mechanical Sciences [online]. 48(2), pp. 160-175. DOI: https://doi.org/10.1016/j.ijmecsci.2005.08.004

[6] S.E. Webster and P.H. Bateson. (1993). Significance of local brittle zones to structural behaviour. Materials Science and Technology. 9(1), pp. 83-92. DOI: https://doi.org/10.1179/mst.1993.9.1.83

[7] P.S. Sheng and V.S. Joshi. (1995). Analysis of heat-affected zone formation for laser cutting of stainless steel, J. Mater. Process. Technol. 53(3-4), pp. 879-892. DOI: https://doi.org/10.1016/09240136(94)01761-O

[8] H.H. Huang, W.T. Tsai and J.T. Lee. (1996). Electrochemical behavior of the simulated heat-affected zone of A516 carbon steel in H2S solution. Electrochimica Acta. 41(7-8), pp. 1191-1199. DOI: https://doi.org/10.1016/0013-4686(95)00470-X

[9] S.O. Al-Mashikhi, J. Powell, A. Kaplan, and K.T. Voisey (2011). Heat affected zones and oxidation marks in fibre laser-oxygen cutting of mild steel. Journal of Laser Applications. 20(4). DOI: https://doi.org/10.2351/1.3614404

[10] M. Sobih, P.L. Crouse and L. Li. (2008). Striation-free fibre laser cutting of mild steel sheets. Appl. Phys. A. 90 (1), pp, 171-174. DOI: https://doi.org/10.1007/s00339-007-4247-7

[11] B.S. Yilbas. (1997). The analysis of CO2 laser cutting. Proc IME B J Eng Manufact. 211(3), pp. 223-232. DOI: https://doi.org/10.1243/0954405971516211

[12] J. Petru and T. Zlamal. (2013). Influence Of Cutting Parameters On HeatAffected Zone After Laser Cutting. Technical Gazette. 20(2) pp. 225230. DOI: https://doi.org/10.22223/tr.2011-2/1888

[13] D.J. Tohmas. (2013). The effect of laser cutting parameters on the formability of complex phase steel. Int J Adv Manuf Technol. 64 (9-12), pp. 1297-1311. DOI: https://doi.org/10.1007/s00170-012-4087-2

[14] W. Schulz, D Becker, J. Franke, R. Kemmerling and G. Herziger. (1993). Heat conduction losses in laser cutting of metals. J Phys Appl Phys. 26(9), pp, 1357-1363. DOI: https://doi.org/10.1088/0022-3727/26/9/003

Mónica López Camargo graduated as a Metallurgical Engineer in 2013 at the Pedagogical and Technological University of Colombia, finished her master's degree in Materials and Manufacturing Processes at the National University of Colombia and receives her degree in 2019.

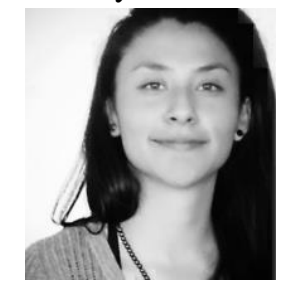
She worked before graduating as an engineer at the Research Institute in Materials Science and Technology in the area of electrochemistry and corrosion until 2012; then it is linked to the oil and gas sector. During his master's studies he obtained an academic scholarship, carrying out teaching activities for the Department of Mechanical and Mechatronic Engineering of the National University until the end of his studies. Publications and participation in congresses of Eng López have focused on powder metallurgy as a training method and its possible applications.

ORCID: https://orcid.org/0000-0003-1680-2908 


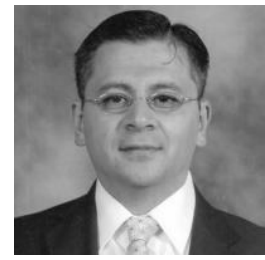

Aldemar Martin Buitrago received the degree in Mechanical Engineering in 1997 from the National University of Colombia and Master in Engineering Industrial Automation in 2008. He is the founder and works for MoviTec Avanzada SAS since 2009 as manager. His professional experience includes: applications of laser technology (laser material processing - cutting and welding), high-speed motion control, development of positioning equipment for laser cutting, general automation, software development for automation (Industrial IoT) and application development in the field of machine learning and Cognitive Computing (Deep Learning).

ORCID: https://orcid.org/0000-0002-9437-1149

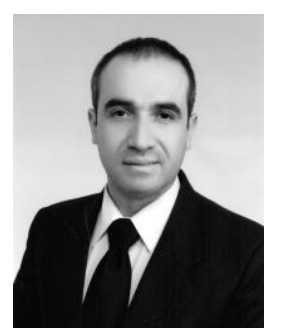

Rodolfo Rodríguez Baracaldo received the Bs. Eng in Mechanical Engineering in 1997 from the Universidad Nacional de Colombia, the MS degree in Materials and Processes in 1999, and the PhD degree in Materials Engineering and Metallurgy in 2008 from Universidad Politécnica de Cataluña, (España). He worked for the Universidad Nacional de Colombia since 2000. Currently, he is a Full Professor in the Mechanical and Mechatronics Department, Facultad de Ingeniería, Universidad Nacional de Colombia. His research interests include: Mechanical Metallurgy, Mechanical Properties of Advanced Meterials, Metal Forming And Computational Materials: Modeling and Simulation.

ORCID: http://orcid.org/0000-0003-3097-9312 